\title{
Role of a Coastal NGO in Attaining Climate Resilience in Bangladesh
}

\author{
Md. Mehedi Hasan1, Mohammed Asaduzzaman Sarker ${ }^{1}$, Mohammed Nasir Uddin1, \\ Md. Zulfikar Rahman', Baokun Lei ${ }^{2}$
}

${ }^{1}$ Department of Agricultural Extension Education, Bangladesh Agricultural University, Mymensingh, Bangladesh ${ }^{2}$ Institute of Agricultural Environment and Resources, Yunnan Academy of Agricultural Sciences, Kunming, China

Email: *masarker@bau.edu.bd

How to cite this paper: Hasan, M.M., Sarker, M.A., Uddin, M.N., Rahman, M.Z. and Lei, B.K. (2018) Role of a Coastal NGO in Attaining Climate Resilience in Bangladesh. American Journal of Climate Change, 7, 187-203.

https://doi.org/10.4236/ajcc.2018.72013

Received: February 1, 2018

Accepted: May 28, 2018

Published: May 31, 2018

Copyright (c) 2018 by authors and Scientific Research Publishing Inc. This work is licensed under the Creative Commons Attribution International License (CC BY 4.0).

http://creativecommons.org/licenses/by/4.0/

\begin{abstract}
The emergence of NGOs represents an organized response by civil society especially in those areas in which the state has either failed to reach or done so inadequately. NGOs have been taking a number of steps to promote discussion and debate about climate change issues. The study was conducted to determine the role of a coastal NGO named Speed Trust in attaining resilience in response to climate change in coastal region; viz. Kalapara sub-district under Patuakhali district. The sample size of the study was 80 respondents. The study followed a mixed-method of research design. Both structured and semi-structured questionnaires were prepared for collecting quantitative and qualitative data from the respondent. The empirical data for the study were collected through personal interviewing of the respondents. The findings of the study revealed that the role of Speed Trust in attaining climate resilience of the study area was varied with the change of aspects of climate resilience. It also indicated that majority ( 80 percent) of the respondents perceived the idea that Speed Trust is playing moderate to highly effective role in attaining climate resilience. While only 1.2 percent had perceived as poor role in attaining resilience in response to climate change. Correlation analysis indicated that among the selected socio-economic characteristics, respondent's education, organizational participation, training on climate resilience, consequence due to climate change and participation in climate resilience program showed positive and significant relationship with the role of Speed Trust in response to climate resilience. Step-wise multiple regression analysis explored that amongst five variables, three independent variables finally entered into the model and the contribution factors are: participation, training, and organizational participation. They are jointly accounted for 62.2 percent of the total variation with perceived role of Speed Trust in attaining climate resilience. It
\end{abstract}


was also established that the absolute majority (100 percent) of the respondents had to face low to medium level problems in getting Sped Trust's services on climate change issues.

\section{Keywords}

Climate Resilience, Role of NGO, Speed Trust, Coastal Region and Bangladesh

\section{Introduction}

Climate change is one of the most important issues to tackle this generation and possibly any generation in history. Bangladesh is a very low energy consuming country; it is pursuing a low carbon growth path, while building its resilience to climate change and reducing the risk of climate change, which represents national development. However, Bangladesh is one of the top 10 nations that are mostly vulnerable to climate change and by the end of the century, Bangladesh may be set to disappear under the waves. The government and non-governmental organizations need to play key role to stop it to be happened [1].

The frequency and intensity of climatic events such as floods, heat waves, tropical cyclones, and droughts are increasing globally due to climate change [2] [3] [4]. Being one of the most climate-vulnerable countries in the world, Bangladesh is highly susceptible to agricultural damage [5] [6] [7] [8]. The potential impacts of climate change by themselves may not always pose the greatest threat to natural coastal systems; in conjunction with other stresses, they could become a serious issue for coastal societies, particularly in those places where the resilience of the coast has been reduced [9]. The main motivation behind this research was to be aimed at better understanding the role of NGOs in attaining climate resilience in the coastal area of Bangladesh to face consequences of climate change.

This research proposes to use critical theories to explore how the resilience of societies vulnerable to climate change can be strengthened through the accumulated role and activities of the NGOs.

However, different researchers worked on perception, awareness, capacity building etc. on climate change issues but research on climate resilience specially in connection with assessing the role of NGOs on climate resilience is not yet conducted. So there is a research gap in that need to be taken into consideration. Thus, the present study was taken into consideration with the aim assessing the role of Speed Trust a leading local NGO working in coastal region on climate change issues. The resilience capacities in response to climate change of the coastal people are not satisfactory [10]. So they demand support and cooperation from different organizations (both GOs and NGOs) to reduce their vulnerabilities and stresses. The main purpose of this research is to find out the NGOs who 
are working on climate resilience on the coastal area. Coastal area of Bangladesh is really vulnerable to climate change due to its physical location. Figure 1 shows coastal region of Bangladesh.

Coastal people of Bangladesh are not aware about the consequences of climate change as well as ways of getting climate resilience. They are involved with different NGOs mainly for economic purposes and few of them are working on improving knowledge of the coastal people about climate resilience [11] [12]. A few coastal NGOs are working on climate change issues to improve the livelihood status of the people to cope up and bounce back from the effects of climate change in many developing countries [13]. The specific objectives of the study were to assess the role of Speed Trust in attaining climate resilience (as perceived by the farmers) as well as to explore the factors responsible for developing climate resilience by the NGO. The study also focused on identifying the problems faced by the farmers in receiving services from the NGOs regarding climate change issues.

\section{Materials and Methods}

\subsection{Study Area}

The study was conducted in Kalapara Sub-District (Upazila) under Patuakhali District of the coastal region of Bangladesh. Two unions (lowermost unit of the local government of Bangladesh) were purposively selected for the study in consultation with the experts, i.e., Upazila Agriculture Officer (UAO) and Upazila Rural Development Officer (URDO) of the same sub-district. Therefore, they were chosen to consult for their expert opinions regarding the study. These two unions are Baliatali and Latachapli. Kalapara is a small town in the Patuakhali district of the Barisal division, in Bangladesh. Kalapara is located at $21.9861^{\circ}$ North latitudes and $90.2422^{\circ}$ East longitudes. Kalapara has 237,831 populations in total (Male 120,514 and Female 117,317) [14]. This region was considered as the study area as it belongs to one of the coastal areas of Bangladesh and vulnerable to climate change. Figure 2 shows the study area.

\subsection{Sampling, Data Collection and Analysis}

Baliatali and Latachapli unions of Kalapara sub-district (upazila) under Patuakhali district was purposively selected for the study on the basis of prior to the research objectives. People of the study area who are small farmers, fishermen and livestock farmers were the target population of this study. The total number of farmers was 11,000 in the study area [14]. From the selected two unions four (4) villages were selected randomly as study villages. The selected villages were Kankunipara, Haripara, Azimour and Misripara. The total number of farmers in these four villages was 615 which constituted the population of the study. About 13 percent of the total farmers of these four villages were selected as sample and finally the sample size constituted 80 farmers. The main occupation of most of the respondents was farming. Very few of them were involved with non-farm activities 


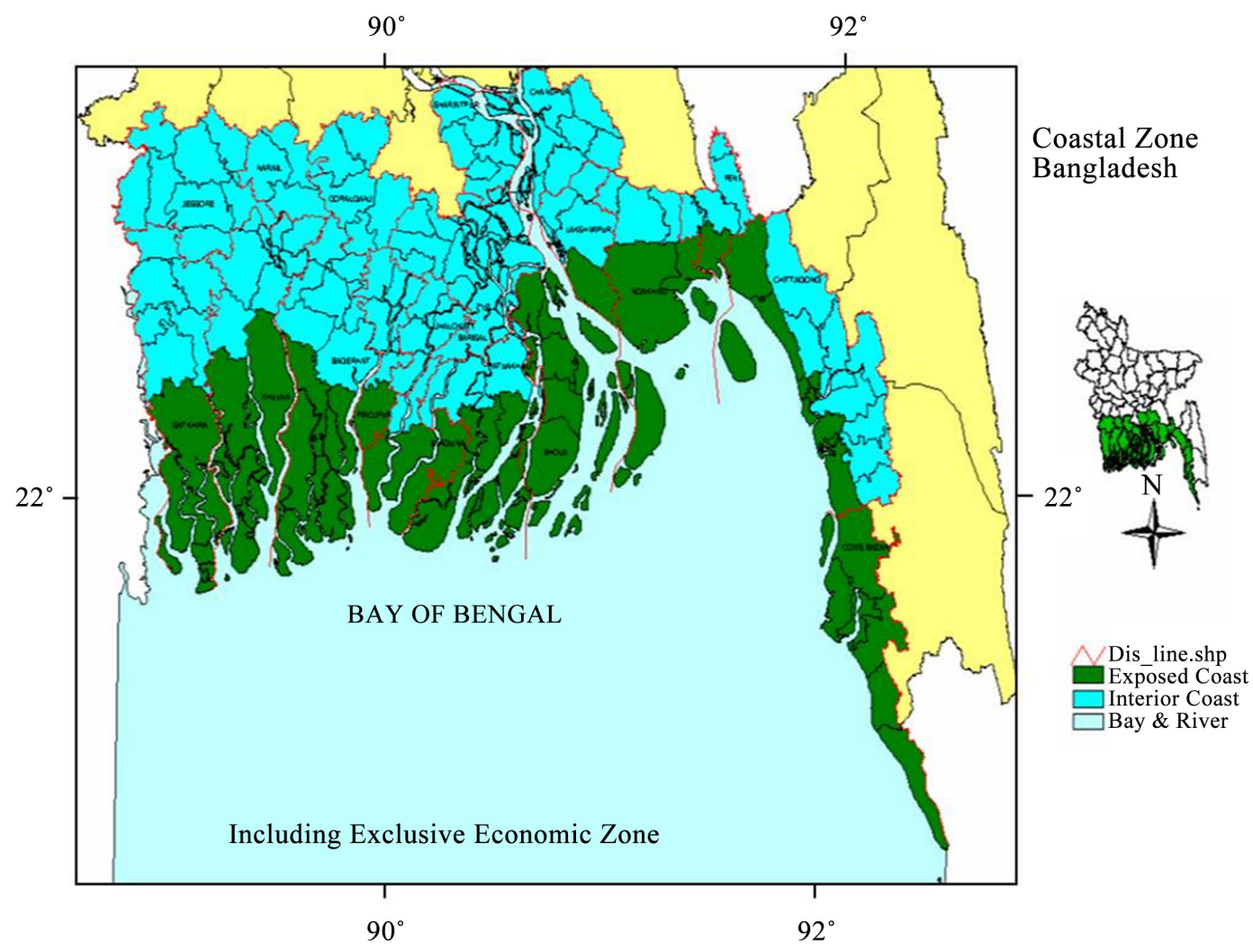

Figure 1. Map of Bangladesh showing disaster prone coastal region of Bangladesh.

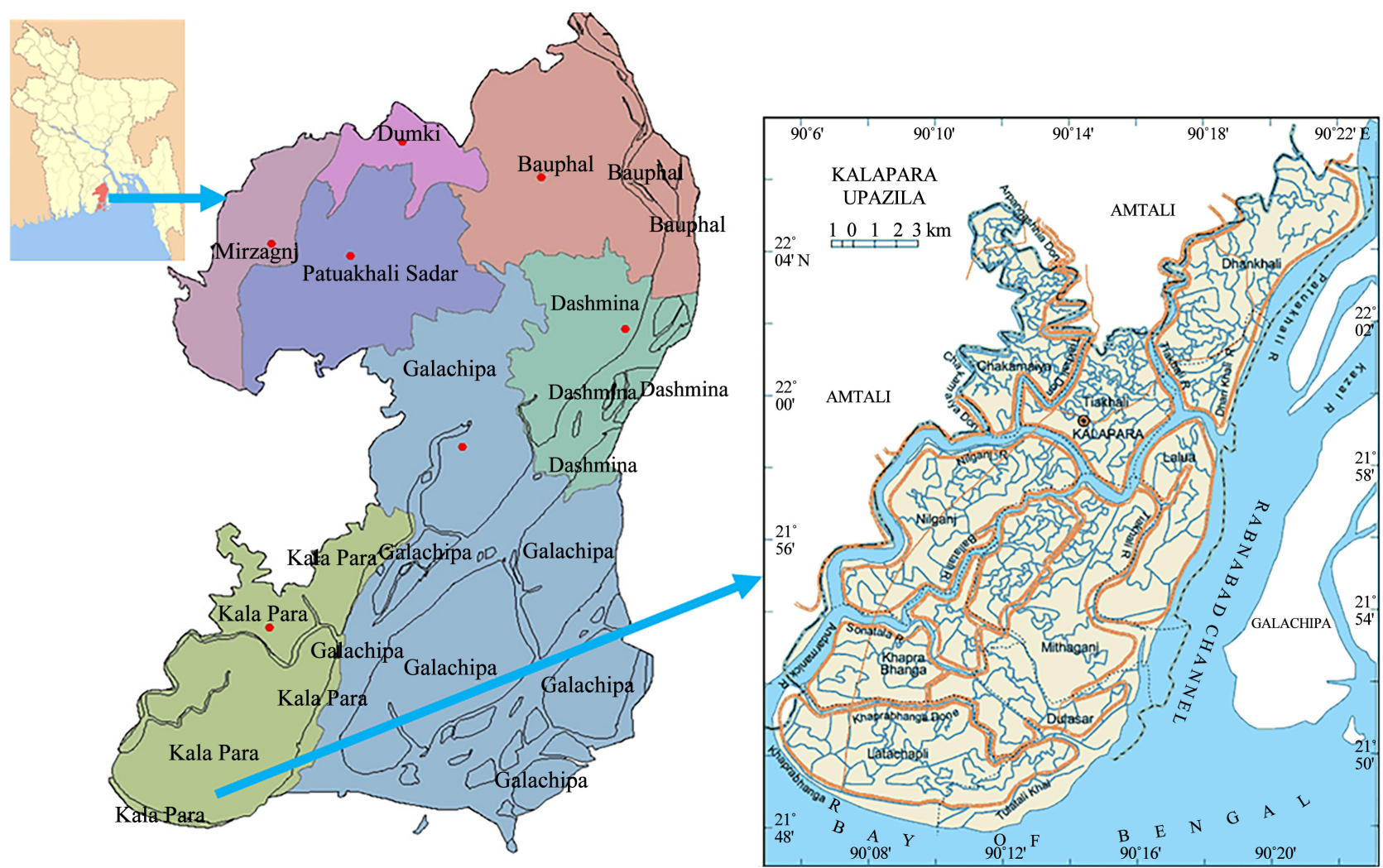

Figure 2. Map of Patuakhali district showing kalapara upazila of bangladesh. 
along with farming as secondary occupation. So the sample population was termed as farmers. A local NGO Speed Trust was purposively selected for this study. It is a very popular NGO in Barisal region which was registered by NGO Affairs Bureau. It has been working in diversified field of development since 1999 [15].

A FGD was carried out in September 2017. One session was conducted in Speed Trust. A semi-structured questionnaire was used to conduct FGD and some basic facts about the climate resilience issues were identified through FGD. In addition, the survey instrument for the study was also polished based on the results of the FGD. The additional information gathered from the FGD was used for interpreting the results of the survey. However, before going to the final data collection, pre-testing with 15 respondents was performed, and the necessary corrections and modifications were done accordingly. The survey was conducted during August to September 2017. Data were collected by two trained enumerators along with the researchers themselves using a structured questionnaire. The enumerators and the researchers first established rapport with the respondents and clearly explained the objectives of the study using local language as far as possible. The questions were clarified whenever any respondent had difficulties to understand. Excellent cooperation was received from the respondents and other people of the study area. Role of a coastal NGO in attaining climate resilience was the focus variable of the study.

A-four point rating scale was used to measure the role of Speed Trust as a focus variable. Thirteen statements obtained from the FGD were incorporated in to the questionnaire and were asked to the respondents against four possible responses such as high, medium, low and no with the corresponding score of 3 , 2, 1 and 0 , respectively. The role of a coastal NGO (Speed Trust) was computed by adding all scores obtained from 13 types of climate resilience approach from which respondents were benefitted. Selected statements cover four dimensions (Adaptation, Vulnerability, Climate change and Resilience) of building climate resilience in Figure 3.

Hence, the scale score ranged from 0 to 39 , where 0 indicates no and 39 indicates high level role in attaining climate resilience. Ranking of the statements was done to prioritize the statements on which providing credit support in rehabilitation due to climate change/disaster were number one.

The collected data were coded, categorized, tabulated and analyzed scientifically. The coded data were put into the computer for statistical analyses. The Statistical Package for Social Science (SPSS) ver. 16.0 computer program was used to analyze the data. Both descriptive and inferential statistics were used to describe the data in this study. Pearson's Product Moment Coefficient of Correlation was used to identify association between the explanatory and focus variable. Besides, multiple linear regression and step-wise multiple regression were employed to identify the individual contribution of the identified factors in explaining the role of Speed Trust in attaining climate resilience. 


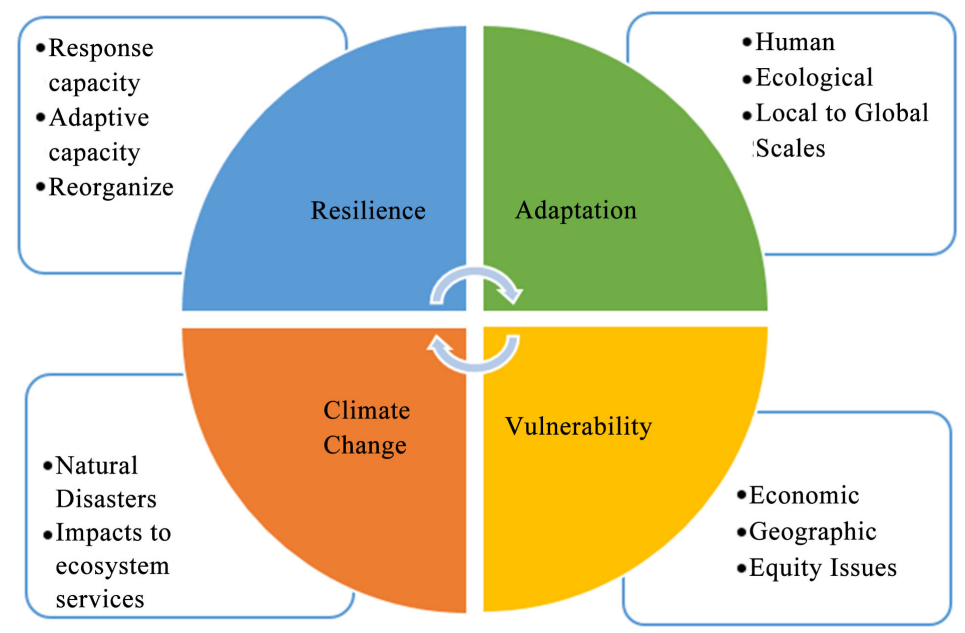

Figure 3. Dimensions of building climate resilience [16].

\section{Results and Discussions}

\section{Socioeconomic Characteristics of the Respondents}

The socioeconomic characteristics of the respondents are shown in Table 1. Data presented in Table 1 show that the age of the respondents ranged between 28 - 59 years. It also shows that the average age of the respondents was 43.65 years with standard deviation 12.44. This means that the majority of the respondents were in the age group of middle aged. The middle aged people are aware about the climate change issues due to their better experience and the NGOs also work with the middle people to mitigate the consequences of climate change and building climate resilience [17].

The findings of the study show that the mean level of education of the respondents was 5.35 with standard deviation 4.08. It is evident from Figure 4 that the half ( 50.0 percent) of the respondents had primary education followed by more than a quarter (29 percent) secondary education. However, a significant portion (11 percent) of the respondents was illiterate. It is very natural that large number of the respondents could not collect advanced knowledge about climate change from various sources due to their poor level of literacy [18].

Figure 4 also exhibits that another 10 percent of the respondents had above secondary level of education. The findings of a study show that the mean family size of the respondents was 4.08 with standard deviation 2.74. It is obvious that the respondents having large family are likely to have more involvement with different climate resilience activities to improve their socio-economic status [19]. This is due to the reason that due to having more number of family members some of them has the opportunity to involve in different income earning and social activities. Data presented in Table 1 show that the annual family income of the respondents ranged between 96 - 350 thousand BDT while the average annual family income was 243.8 thousand BDT with standard deviation 109.9. It indicates that majority of the respondents of the study area were resource medium [17]. However, it was evident from the findings that the observed organizational 
Table 1. Socioeconomic characteristics of the respondents $(n=80)$.

\begin{tabular}{ccccc}
\hline Characteristics & Scoring System & Possible score & $\begin{array}{c}\text { Observed } \\
\text { score }\end{array}$ & Mean \pm SD \\
\hline Age & Actual Years & Unknown & $28-59$ & $43.65 \pm 12.44$ \\
Level of education & Years of schooling & Unknown & $13-18$ & $5.35 \pm 4.08$ \\
Family size & Number & Unknown & $3-9$ & $4.08 \pm 2.74$ \\
$\begin{array}{c}\text { Annual family income } \\
\text { Organizational } \\
\text { Participation }\end{array}$ & "000" BDT & Unknown & $96-350$ & $243.8 \pm 109.9$ \\
$\begin{array}{c}\text { Communication } \\
\text { exposure }\end{array}$ & Scale score & $0-24$ & $1-15$ & $3.88 \pm 2.46$ \\
$\begin{array}{c}\text { Training received on } \\
\text { climate resilience }\end{array}$ & Number of days & Unknown & $0-3$ & $3.78 \pm 2.80$ \\
$\begin{array}{c}\text { Consequences due to } \\
\text { climate change }\end{array}$ & "000" BDT* & Unknown & $30-320$ & $208.2 \pm 98.92$ \\
$\begin{array}{c}\text { Participation in } \\
\text { climate resilience } \\
\text { program }\end{array}$ & Scale score & $0-12$ & $1-36$ & $24.95 \pm 5.80$ \\
\hline
\end{tabular}

${ }^{*} \mathrm{SD}=$ Standard Deviation; ${ }^{*} \mathrm{BDT}=$ Bangladeshi Taka.

Distribution of the respondents based on their level of education

mIlliterate $(0) \quad$ Primary (1-5) $\square$ Secondary (6-10) $\quad$ Above secondary (Above 10)

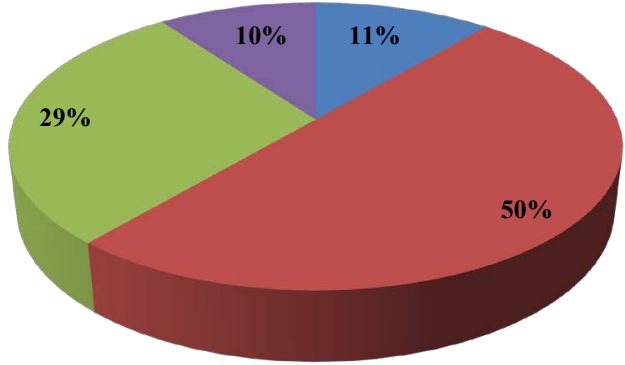

Figure 4. Distribution of the respondents based on their level of education.

participation score of the respondents ranged between $1-15$ in against of the possible score of $0-24$. The findings also show that the mean organizational participation score of the respondents was 3.88 with standard deviation 2.46.

Table 1 shows that the observed communication exposure score ranged between 3 - 36 in against of the possible score of 0 - 51. It is revealed from Table 1 that the mean communication exposure score of the respondents was 24.95 with standard deviation 5.80

Figure 5 depicts that the absolute majority (95 percent) of the respondents were found to have low to medium level communication exposure. It implies that their mobility and participation in development activities is relatively poor this findings is supported by findings of Yeasmin [18]. Like organization participation the average training received score of the respondents was 3.78 with standard deviation 2.80. This means that a large portion of the respondents need 
to provide training to mitigate the consequences and cope up with the situation in response to climate change [17] [18]. However, the findings of the study show that the level consequences of respondents due to climate change ranged between 30 - 320 thousand BDT. Data furnished in Table 1 also indicates that the mean economic consequences of the respondents due to climate change were 208.2 thousand BDT with standard deviation 98.92.

Table 1 shows that the observed score on participation in climate resilience programme of the respondents ranges between 1 - 9 in against of the possible score of 1 - 12. It is also reported in Table 1 that the mean score on participation in climate resilience programme of the respondents was 6.73 with standard deviation 3.22. Figure 6 demonstrates that more than one-third (38.8 percent) of the respondents had medium level participation in climate reliance programmes. While, another one-third (33.8) percent had high level participation. It is also evident that more than a quarter (27 percent) of the respondents has low level participation in climate resilience programmes. Thus, it can be concluded in a way that it is still need to involve more number of coastal people in climate resilience progarmmes.

Distribution of the respondnets based on their communication exposure

- Low (up to 17) $\quad$ Medium (18-34) $\quad$ High (above 34)

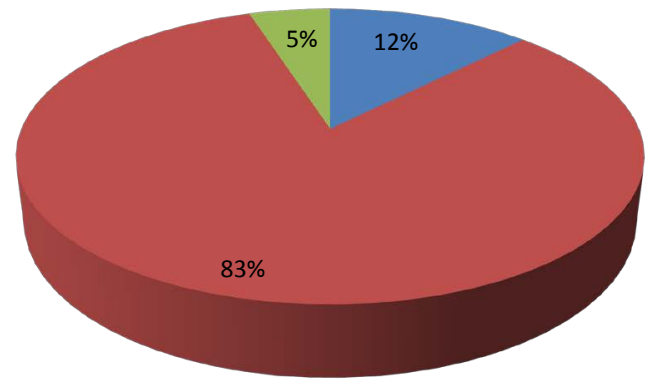

Figure 5. Distribution of the respondents based on their communication exposure.

Distribution of the respondents based on their level of paticipation in climate resilience programme

Low ( up to 4) $\quad$ Medium(5-8) $\quad$ High (above 8)

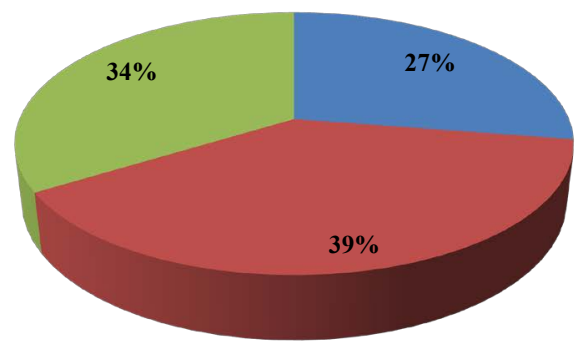

Figure 6. Distribution of the respondents based on their level of participation in climate resilience programme. 
The main thrust of the study was to assess the farmers' perceived role of Speed Trust in attaining climate resilience in the study area. Thus, data were collected using a four point rating scale (waitage 3,2, 1 and 0 respectively) and compiled the responses of a respondent against selected 13 statements. Thus the total role score was ranged between 0 - 39, where 0 indicating poor role and 39 indicating highly effective role (Table 2 ).

Table 2 exhibits that the absolute majority ( 98.8 percent) of the respondents have perceived the idea that Speed Trust is playing moderate to highly effective role in attaining climate resilience in the study area. Findings also clarified that the highest proportion ( 80.0 percent) of the respondents had perceived the idea that Speed Trust is playing moderate role in attaining climate resilience. While a significant portion (18.8 percent) of the respondents posses the idea that Speed Trust is playing highly effective role in attaining climate resilience and only 1.2 percent respondents opined that it has poor role in attaining climate resilience. NGO Speed Trust actively started its work in climate resilience issues since its inception in the study area so its performance is satisfactory to the beneficiaries.

A four point rating scale was used to determine the role of Speed Trust in attaining climate resilience in the study area. Different statements regarding climate resilience issues were obtained from the FGD conducted with the Speed Trust beneficiaries. Table 3 represents the statement wise respondents' perception as well as their rank order regarding the role of Speed Trust in attaining climatic resilience. The relevant statements (shown in Table 3) were structured under four major dimensions like, 1) climate change; 2) vulnerability; 3) climate resilience; and iv) adaptation [16].

Due to climate change the weather pattern of the coastal area being changed and different NGOs specifically Speed Trust has been working on different aspects of climatic resilience issues. Table 3 also shows that "Speed Trust provides grants or aids to the poor people for reducing dependency on natural resource" got the first rank among the statements with the total role index (RI) of 187.

So it is understand that Speed Trust's support is working effectively with providing grants or aids during and after natural disasters is contributing efficiently in reducing poor peoples' dependency on natural resources. "Activities of Speed Trust are mostly humanitarian. They help and support us by giving grants after flood and cyclone"-FGD participants. Works for infrastructure reorganization and development caused by climate disaster (RI 174) was the second highest rank among the statements. After the natural disaster infrastructure system of the coastal area become collapse. Speed Trust works for infrastructure development to attaining climate resilience in the coastal area. Knowledge generation on consequence of climate change RI (167) and stood third in the rank order. Local rural people of coastal area have little knowledge about climate change and its resilience, so they did not identify the ultimate result of climate change [20]. Speed Trust arrange different training program about climate change so they aware about natural disaster. "Before cyclone or any other natural disaster the 
Table 2. Distribution of the respondents based on their resilience score.

\begin{tabular}{cccc}
\hline \multirow{2}{*}{$\begin{array}{c}\text { Respondent Categories based on } \\
\text { perceived role of Speed Trust }\end{array}$} & \multicolumn{2}{c}{ Respondents } & Mean $\pm \mathrm{SD}^{*}$ \\
\cline { 2 - 3 } & No. & $\%$ & \\
\hline Poorly effective $(0-13)$ & 1.0 & 1.2 & $23.18 \pm 3.58$ \\
Moderately effective $(14-26)$ & 64 & 80.0 & \\
Highly effective role $(27-39)$ & 15 & 18.8 & \\
\hline
\end{tabular}

${ }^{*} \mathrm{SD}=$ Standard Deviation.

Table 3. Statement-wise role of Speed Trust as perceived by the respondents $(n=80)$.

\begin{tabular}{|c|c|c|c|c|c|c|c|}
\hline \multirow{2}{*}{ Aspects } & \multicolumn{4}{|c|}{ No. of Respondents } & \multirow{2}{*}{ RI } & \multirow{2}{*}{$\mathbf{M}$} & \multirow{2}{*}{ RO } \\
\hline & $\mathrm{H}$ & $\mathbf{M}$ & $\mathrm{L}$ & $\mathbf{N}$ & & & \\
\hline \multicolumn{8}{|c|}{ Climate Change } \\
\hline $\begin{array}{l}\text { Knowledge generation on consequence of climate } \\
\text { change }\end{array}$ & 28 & 31 & 21 & 0 & 167 & 2.08 & 3 \\
\hline $\begin{array}{l}\text { Understanding development in importance of } \\
\text { ecosystem conservation (forest \& aquatic) }\end{array}$ & 31 & 22 & 21 & 6 & 158 & 1.97 & 4 \\
\hline $\begin{array}{l}\text { General awareness creation on climate change for } \\
\text { better livelihood and wellbeing }\end{array}$ & 15 & 30 & 24 & 11 & 129 & 1.61 & 11 \\
\hline \multicolumn{8}{|l|}{ Vulnerability } \\
\hline $\begin{array}{l}\text { Providing credit support in rehabilitation due to } \\
\text { climate change/disaster }\end{array}$ & 22 & 18 & 19 & 21 & 121 & 1.51 & 12 \\
\hline $\begin{array}{l}\text { Provides grants or aids to the poor people for reducing } \\
\text { dependency on natural resource }\end{array}$ & 47 & 16 & 14 & 3 & 187 & 2.33 & 1 \\
\hline Contribution in social capital formation & 13 & 28 & 21 & 18 & 116 & 1.45 & 13 \\
\hline \multicolumn{8}{|c|}{ Climate Resilience } \\
\hline $\begin{array}{l}\text { Ability development of the community people to } \\
\text { response with the situation during natural calamities }\end{array}$ & 20 & 25 & 20 & 15 & 150 & 1.62 & 7 \\
\hline Capacity building on disaster risk reduction & 18 & 24 & 29 & 9 & 131 & 1.63 & 10 \\
\hline $\begin{array}{l}\text { Adaptive capacity building to the vulnerable people to } \\
\text { cope up in adverse situation }\end{array}$ & 18 & 31 & 20 & 11 & 136 & 1.70 & 8 \\
\hline $\begin{array}{l}\text { Works for infrastructure reorganization and } \\
\text { development caused by climate disaster }\end{array}$ & 39 & 20 & 17 & 4 & 174 & 2.17 & 2 \\
\hline \multicolumn{8}{|l|}{ Adaptation } \\
\hline $\begin{array}{l}\text { Disaster management and climate change program by } \\
\text { the NGOs }\end{array}$ & 24 & 29 & 23 & 4 & 153 & 1.91 & 5 \\
\hline $\begin{array}{c}\text { Leadership development and group formation in } \\
\text { climate perspective }\end{array}$ & 24 & 19 & 24 & 13 & 134 & 1.67 & 9 \\
\hline $\begin{array}{l}\text { Agriculture and food security program for mitigating } \\
\text { consequence of climate change }\end{array}$ & 17 & 21 & 29 & 13 & 152 & 1.52 & 6 \\
\hline
\end{tabular}

Code: $\mathrm{H}=$ High (3); M = Medium (2); L = Low (1); RI = Resilience Index; M = Mean and RO = Rank Order.

Speed Trust workers comes to us and teach us how to escape and prevent loss from natural disaster. They also teach us about consequence of the climate change"-FGD participants. Contribution in social capital formation got the last position in the rank order with RI 116. Speed Trust works for the vulnerable 
people but they may not be able to contribute much as to social capital formation of the local people.

To determine the association between the socioeconomic characteristics of the respondents which are the explanatory variables of the study and the focus variable, i.e., role of a coastal NGO in attaining climate resilience, a null hypothesis $\left(\mathrm{H}_{0}\right)$ was formulated. $\mathrm{H}_{0}$ indicates that there is no association between the explanatory and focus variables. Pearson's Product Moment Coefficient of Correlation ( $r$ ) was used to test the $\mathrm{H}_{0}$. To reject the $\mathrm{H}_{0}, 1$ and 5 percent level of probability was taken into consideration. Table 4 represents the summary correlation test between the variables.

From Table 4, it is evident that out of nine characteristics of the respondents, five characteristics such as level of education, organizational participation, training received on climate resilience, consequence due to climate change and participation in climate resilience programme had positive and significant association with the perceived role of Speed Trust in attaining climate resilience.

Multiple linear regression analysis was employed to explore the factors and their contribution in predicting the focus variable, i.e., role of a Speed Trust in attaining climate resilience. Table 5 represents the outputs of the multiple regression analysis. The results of the study show that three explanatory variables out of nine were significant with the $\mathrm{F}$ value of 12.78 and adjusted $\mathrm{R}^{2}$ value of 0.622. Therefore, the results imply that about 62.2 percent of the variation in the perceived role of Speed Trust in attaining climate resilience was explained by the combined effects of explanatory variables. The coefficient of organization participation $(\mathrm{t}=1.432$ and $\mathrm{p}<0.05)$, training on climate resilience $(\mathrm{t}=1.304$ and $\mathrm{p}$ $<0.05)$, participation in climate resilience program $(t=6.26$ and $p<0.01)$ were significant. The results imply that these factors influenced the perceived role of the NGO Speed Trust in attaining climate resilience in the study area. The results also revealed that organizational participation of the respondents had a positive coefficient, i.e., the people who are more involved in organization likely to cope up with the adverse climatic condition. This result is in line with the study in Kerala state in India conducted by [12].

This may be due to that participation in different organizations by the respondents has increased in the recent time due to the extended activities of GOs and NGOs. Thus, people's awareness about climate resilience has also been increased to some extent compared to previous. Training on climate resilience was positive and significant for the respondents in attaining climate resilience in the study area. The result implies that increased the climatic training provided by the NGOs are better the climate resilience. However, findings showed that coastal people have relatively poor access to climatic issues [21]. It is also supported by the findings of the study of Nhemachena and Hassan that higher participation in the training program increased resilience capacities of the people [22]. Participation in climate resilience program also emerged as a positive and significant factor in role of Speed Trust in attaining climate resilience. It may be 
Table 4. Correlation between socioeconomic characteristics and role of a coastal NGO in attaining climate resilience $(\mathrm{n}=80)$.

\begin{tabular}{cc}
\hline Socioeconomic characteristics & Correlation coefficient $(\mathrm{r})$ with $\mathbf{7 8 ~ \mathrm { df }}$ \\
\hline Age & 0.103 \\
Level of education & $0.433^{* *}$ \\
Family size & 0.048 \\
Annual family income & -0.035 \\
Organizational participation & $0.420^{* *}$ \\
Communication exposure & 0.075 \\
Training on climate resilience & $0.585^{* *}$ \\
Consequence due to climate change & $0.301^{*}$ \\
Participation in climate resilience programme & $0.766^{* *}$ \\
\hline
\end{tabular}

Degrees of Freedom $(\mathrm{df})=78$, Tabulated value $(\mathrm{r})=0.250$ ( 5 percent level) and 0.325 ( 1 percent level). ${ }^{\star}$ Correlation is significant at $5 \%$ level of probability, ${ }^{* *}$ Correlation is significant at $1 \%$ level of probability.

Table 5. Summary of multiple linear regression explaining focus variable $(n=80)$.

\begin{tabular}{|c|c|c|c|c|}
\hline Explanatory variable & $\begin{array}{l}\text { Unstandardized } \\
\text { Coefficients (B) }\end{array}$ & $\begin{array}{l}\text { Standardized } \\
\text { Coefficients } \\
\text { (Beta) }\end{array}$ & "t" value & F value \\
\hline Age & -0.018 & -0.061 & -0.719 & \\
\hline Level of education & 0.046 & 0.080 & 0.898 & \\
\hline Family size & 0.006 & 0.004 & 0.046 & \\
\hline Annual family income & 0.002 & 0.067 & 0.645 & \\
\hline Organizational participation & 0.099 & 0.149 & $1.432^{*}$ & $12.78^{\star x}$ \\
\hline Communication exposure & -0.007 & -0.012 & -0.126 & \\
\hline Training received on climate resilience & 0.092 & 0.144 & $1.304^{*}$ & \\
\hline Consequence due to climate change & 0.002 & 0.038 & 0.464 & \\
\hline $\begin{array}{l}\text { Participation in climate resilience } \\
\text { programme }\end{array}$ & 0.276 & 0.648 & $6.265^{* *}$ & \\
\hline \multicolumn{5}{|c|}{$\mathrm{R}^{2}=0.632$ and Adjusted $\mathrm{R}^{2}=0.622$} \\
\hline
\end{tabular}

Significant if $\mathrm{p}<0.05$, Level of significance $=95 \%$.

because the respondents having higher partnership in climate resilience program have higher capacities to cope up and mitigate the loss of climate resilience. This result is in line with [10] [23].

To understand the contribution of each variable to the respondents' variation in the role of Speed Trust in attaining climate resilience in the study area, a step-wise multiple regression analysis was conducted. Table 6 represents the output of the analysis.

The findings indicate that out of three significant socioeconomic characteristics obtained from the multiple linear regressions, all three such as participation in climate resilience program, training on climate resilience program and orga- 
nizational participations entered into the model. The findings also indicate these three variables jointly can explain 62.2 percent variation in the perceived role of Speed Trust in attaining climate resilience in the study area. The first variable entered into the model was participation in climate resilience program of the respondents $\left(R^{2}=0.581\right)$ which had the highest contribution (58.1 percent) in explaining the variation in the focus variable. This implies that with the increase of participation in climate resilience program, the respondents are more likely to bounce back from natural hazards. The respondents with higher participation in climate resilience program are more capable to cope up with the consequences of climate change [24]. This is may be due to the reason that the respondent having more knowledge about the effect of climate change and importance of climate resilience approach. The second variable entered into the model was training on climate resilience of the respondents and it is shown that 3.5 percent variation of the focus variable was explained solely by the training on climate resilience of the respondents. The finding reveals that with the increase in training of the respondents, they are more likely to coping with the climate change and attain climate resilience in the study area. The reason behind this may be that the trained respondents possess a high level of knowledge regarding climate resilience through their experience gather from training. The third variable entered into the model was organizational participation of the respondents which accounts for 0.6 percent contribution in explaining the focus variable. Organizational participation of the respondents helps to get necessary information from different source according to their need on climate resilience. People involved with different organization so they can informed and concerned about the climate resilience [25]. Participation in different organization helps them to act as opinion leader to express their felt need before and after the disaster.

\section{Problems Faced by the Respondents in Getting Access to NGO's Services on Climate Change Issues}

Table 7 shows that the highest proportion 58.8 percent of the respondents had low problems while 41.2 percent of them had medium and no one faced high level problems in getting access to NGO's services on climate change issues.

Respondents gave their responses as high, medium, low and not at all against each problem included in problem confrontation scale. To ascertain the extent of seriousness of problems a Problem Confrontation Index (PCI) value was computed (Table 8). Table 8 showed some problems of the respondents during getting service from NGOs and their ranking positions on the basis of severity. From the rank order it was found that "Poor participation in disaster management and climate change program" was the first problem of the respondents. Respondent was not participating in climate change and its related program because of their low level education and lack of awareness so they could not take any precautions measures to avoid disaster [17]. "Climate resilience program did not arranged frequently by the NGOs; again we were not informed about disaster management program properly" -FGD participants. 
Table 6. Summary of stepwise multiple regression analysis $(n=80)$.

\begin{tabular}{|c|c|c|c|c|c|}
\hline $\begin{array}{l}\text { Model } \\
\text { No. }\end{array}$ & Variables entered & $\begin{array}{l}\text { Unstandardized } \\
\text { coefficient } \\
\text { (B) }\end{array}$ & $\begin{array}{l}\text { Standardized } \\
\text { coefficient } \\
\text { (Beta) }\end{array}$ & $\begin{array}{c}\text { Adjusted } \\
\mathrm{R}^{2}\end{array}$ & $\begin{array}{c}\mathrm{R}^{2} \\
\text { Change } \\
(\% \text { contribution })\end{array}$ \\
\hline 1 & $\begin{array}{c}\text { Constant }+ \text { Participation in } \\
\text { CRP }\end{array}$ & 0.326 & 0.766 & 0.581 & 58.1 \\
\hline 2 & $\begin{array}{l}\text { Constant }+ \text { Participation in } \\
\text { CRP + Training received on } \\
\text { climate resilience }\end{array}$ & 0.390 & 0.827 & 0.616 & 3.5 \\
\hline 3 & $\begin{array}{c}\text { Constant + Participation in } \\
\text { CRP + Training received on } \\
\text { climate resilience }+ \\
\text { organizational participation }\end{array}$ & 0.397 & 0.841 & 0.622 & 0.6 \\
\hline
\end{tabular}

Table 7. Distribution of the respondents according to their problems in getting NGO's services.

\begin{tabular}{cccc}
\hline \multirow{2}{*}{ Category } & \multicolumn{2}{c}{ Respondents } & Mean \pm SD \\
\cline { 2 - 3 } & Number & Percentage (\%) & \\
\hline Low problems (Up to 11) & 47 & 58.8 & $11.11 \pm 3.70$ \\
Medium problems (12- 22) & 33 & 41.2 & \\
High problems (above 22) & 0.0 & 0.0 & \\
\hline
\end{tabular}

Table 8. Problems faced by the respondents in getting NGO's services on climate change issues $(n=80)$.

\begin{tabular}{|c|c|c|c|c|c|c|}
\hline \multirow{2}{*}{ Name of the problems } & \multicolumn{4}{|c|}{ Extent of problems } & \multirow{2}{*}{ PCI } & \multirow{2}{*}{$\mathrm{RO}$} \\
\hline & $\mathrm{H}$ & M & $\mathrm{L}$ & $\mathrm{N}$ & & \\
\hline Unable to build rapport with the NGOs worker & 11 & 14 & 27 & 28 & 88 & 5 \\
\hline Unavailability of the NGOs workers & 6 & 16 & 30 & 28 & 80 & 8 \\
\hline Lack of leadership and group affiliation & 9 & 16 & 40 & 15 & 99 & 4 \\
\hline Lack of awareness on NGO services & 18 & 14 & 34 & 14 & 116 & 2 \\
\hline Poor communication and limited capacity of the NGOs & 10 & 14 & 25 & 31 & 83 & 6 \\
\hline Political interference in getting membership & 14 & 6 & 12 & 48 & 66 & 10 \\
\hline $\begin{array}{l}\text { Poor participation in disaster management and climate change } \\
\text { program }\end{array}$ & 26 & 14 & 19 & 21 & 125 & 1 \\
\hline Negative perception regarding NGO & 5 & 13 & 15 & 47 & 56 & 11 \\
\hline Scarcity of credit for climate resilience program & 8 & 21 & 11 & 40 & 77 & 9 \\
\hline $\begin{array}{l}\text { Importance of the respondents as vital stakeholders for } \\
\text { programs of climate resilience }\end{array}$ & 19 & 12 & 28 & 21 & 109 & 3 \\
\hline Less interest to conduct programs related to climate change & 6 & 19 & 26 & 29 & 82 & 7 \\
\hline
\end{tabular}

Code: $\mathrm{H}=$ High (3), $\mathrm{M}=$ Medium (2), L = Low (1), N = Not at all (0), PCI = Problem Confrontation Index, $\mathrm{RO}=$ Rank order.

"Lack of the awareness on the NGO services" was the second problem of the respondents. It is also due to low level of education and training facilities. Dif- 
ferent organizations are not always organized climate change related program [21].

The third problem faced by the respondents was "Importance of the respondents as vital stakeholders for programs of climate resilience". "The NGOs which are available in coastal area are not always working with small respondents. Again most NGOs provide credit to the medium income family so they are the main stakeholders of these NGOs" -FGD participants. However, NGOs may not be always aware and concerned about climate resilience.

\section{Conclusions}

Climate services form NGOs play a key role in supporting the resilience of people and communities. The role of Speed Trust in attaining climate resilience was satisfactory, because all aspects of climate resilience were fulfilled by the Speed Trust. However, being a local NGO Speed Trust has limited organizational and financial capacity to fight against wide spread consequences of climate change in the coastal areas. The study categorically showed that participation in climate resilience programme of the local people can play the highest role in building climate resilience in the coastal area. Speed Trust is trying to provide services to the smallest portion of the total coastal population with its limited capacity. However, if other national and international NGOs come up with the view of involving more coastal people in climate resilience programme that will be very effective in attaining climate resilience in the vulnerable coastal region. In addition, Speed Trust's role in attaining climate resilience can also be further strengthened through better financial support by the Government and other donor agencies. The study also explored that access to training on climate change issues is another important factor on the way of building climate resilience. Thus, it is need of changing NGO's service policy from micro-credit paradigm to capacity building approach through organizing more training for the beneficiaries. To let it happen, partnership with government organizations is very important. The study also revealed that organizational participation is also important with their perceived role of a NGO in attaining climate resilience. It means that people has better access to training on climate change issues and the higher participation in climate resilience program and affiliation with different organizations can play efficient role in building climate resilience with the support of NGOs. Findings also showed that all of the respondents had to face low to medium problems in getting access to Speed Trust's services on climate change issues, which indicates its better climate related services to the clientele. However, based on the perception of the farmers in the study area as coastal NGO, Speed Trust is playing a key role in attaining climate resilience in the study area though it has limited capacity to contribute. Thus, this is very important to have some extended programmes by GOs and NGOs and/or GO-NGO collaborating programmes in attaining climate resilience in the coastal region of Bangladesh. 


\section{References}

[1] Mahmood, S.A. (2012) Impact of Climate Change in Bangladesh: The Role of Public Administration and Government's Integrity. Journal of Ecology and the Natural Environment, 4, 223-240.

[2] Huq, N. and Hugé, J. (2010) Workers' Rights in Climate Change Policies: The Case of Adaptation Programmes in Small Island Developing States. International Journal of Labour Research, 2, 163-185. https://doi.org/10.5848/ILO.978-9-221254-79-9_3

[3] Field, C.B., Barros, V., Stocker, T.F., Qin, D., Dokken, D.J., Ebi, K.L., Mastrandrea, M.D., Mach, K.J., Plattner, G.-K., Allen, S.K., et al., Eds. (2012) Managing the Risks of Extreme Events and Disasters to Advance Climate Change Adaptation. A Special Report of Working Groups I and II of the Intergovernmental Panel on Climate Change. IPCC, Cambridge University Press, Cambridge, UK, New York, NY.

[4] IPCC. (2014) Summary for Policymakers. In: Field, C.B., Barros, V.R., Dokken, D.J., Mach, K.J., Mastrandrea, M.D., Bilir, T.E., Chatterjee, M., Ebi, K.L., Estrada, Y.O., Genova, R.C., et al., Eds., Climate Change 2014: Impacts, Adaptation, and Vulnerability. Part A: Global and Sectoral Aspects. Contribution of Working Group II to the Fifth Assessment Report of the Intergovernmental Panel on Climate Change, Cambridge University Press, Cambridge, UK, New York, NY, 1-32.

https://doi.org/10.1017/CBO9781107415379.003

[5] Xu, J., Grumbine, R.E., Shrestha, A., Eriksson, M., Yang, X., Wang, Y. and Wilkes, A. (2009) The Melting Himalayas: Cascading Effects of Climate Change on Water, Biodiversity, and Livelihoods. Conservation Biology, 23, 520-530.

https://doi.org/10.1111/j.1523-1739.2009.01237.x

[6] Gain, A.K., Giupponi, C. and Renaud, F.G. (2012) Climate Change Adaptation and Vulnerability Assessment of Water Resources Systems in Developing Countries: A Generalized Framework and a Feasibility Study in Bangladesh. Water, 4, 345-366. https://doi.org/10.3390/w4020345

[7] Hossain, Z. and Huq, N. (2013) Institutions Matter for Urban Resilience: The Institutional Challenges in Mainstreaming Climate Smart Disaster Risk Management in Bangladesh. In: Leal Filho, W., Ed., Climate Change and Disaster Risk Management, Climate Change Management, Springer, Berlin, Germany, Heidelberg, Germany, 169-191.

[8] Huq, N., Hossain, Z., Hasan, R. and Azad, A.M. (2012) "Climate Proofing” Water Resources Development Policy: The Evidence from Bangladesh. In: Leal Filho, W., Ed., Climate Change and the Sustainable Use of Water Resources, Climate Change Management, Springer, Berlin, Germany, Heidelberg, Germany, 389-400. https://doi.org/10.1007/978-3-642-22266-5_24

[9] IPCC. (2007) Climate Change 2007. Synthesis Report. Contribution of Working Groups I, II and III to the Fourth Assessment Report of the Intergovernmental Panel on Climate Change (IPCC). IPCC, Geneva.

[10] Iwuchukwu, J.C., Nwankwo, O.J. and Ogbonna, O.I. (2014) Knowledge and Roles of Non Governmental Organizations (NGOs) in Climate Change Mitigation and Adaptation in Anambra State. Journal of Agricultural Extension, 18, 126-130. https://doi.org/10.4314/jae.v18i2.13

[11] Islam, R. (2007) Pre- and Post-Tsunami Coastal Planning and Land-Use Policies and Issues in Bangladesh, FAO Corporate Document Repository. http://www.fao.org/docrep/010/ag 12 4e/A G124E05.htm

[12] Divakarannair, N. (2007) Livelihood Assets and Survival Strategies in Coastal Communities in Kerala, India. Department of Geography, University of Victoria, 
British Columbia.

[13] Agarwal, A. (2008) Role of NGOs in the Protection of Environment. Journal of Environmental Research and Development, 2, 933-939.

[14] BBS. (2017) Statistical Yearbook of Bangladesh. Bangladesh Bureau of Statistics, Statistics Division, Ministry of Planning, Government of the People's Republic of Bangladesh.

[15] Speed Trust. (2017) Speed Trust Website. http://www.speedtrust.org/

[16] Smith, B. and Johanna, W. (2006) Adaptation, Adaptive Capacity and Vulnerability. Global Environmental Change, 16, 282-292. https://doi.org/10.1016/j.gloenvcha.2006.03.008

[17] Billah, M. (2013) Adaptation of Farming Practices by the Smallholder Farmers in Response to Climate Change Status. Unpublished Master's Thesis, Department of Agricultural Extension Education, Bangladesh Agricultural University, Mymensingh.

[18] Mandal, S. (2011) Improvement of Livelihoods of the Farmers Due to Extension Activities of Krishi Gyan Samprosaran Kendra (KGSK). Unpublished Master's Thesis, Department of Agricultural Extension Education, Bangladesh Agricultural University, Mymensingh.

[19] Hossain, M.J. (2013) Changes of Livelihood Status of the Farmers Due to Climate Change in a Selected Area of Satkhira District. Unpublished Master's Thesis, Department of Agricultural Extension Education, Bangladesh Agricultural Univesity, Mymensingh.

[20] Yeasmin, M.S. (2013) Training Needs of the Integrated Fish Farmers on Integrated Fish Farming. Unpublished Master's Thesis, Department of Agricultural Extension Education, Bangladesh Agricultural University, Mymensingh.

[21] Saroar, M. and Routray, J.K. (2010) Why Does Climate Change Awareness Differ? Lessons Learned from Bangladesh. 2nd International Conference on Climate Change, Sustainability and Development in Semi-Arid Regions, Fortaleza, 16-20 August 2010, 48-53.

[22] Nhemachena, C. and Hassan, R. (2008) Determinants of African Farmers Strategies for Adapting to Climate Change: Multinomial Choice Analysis. African Journal of Research and Education, 2, 83-104.

[23] Semenza, J.C., Hall, D.E., Wilson, D.J., Bontempo, B.D., Sailor, D.J. and George, L.A. (2008) Public Perception of Climate Change: Voluntary Mitigations and Barriers to Behaviour Change. American Journal of Preventive Medicine, 35, 497-487. https://doi.org/10.1016/j.amepre.2008.08.020

[24] Hasan, Z. and Akhter, S. (2011) Determinants of Public Awareness and Attitudes on Climate Change in Urban Bangladesh: Dhaka as a Case. European Journal of Social Sciences, 21, 154-162.

[25] Ekpoh, U.I. and Ekpoh, I.J. (2011) Assessing the Level of Climate Change Awareness among Secondary School Teachers in Calabar Municipality: Implication for Management Effectiveness. International Journal of Humanities and Social Science, 3, 106-110. 